\title{
Landsat Surface Reflectance Climate Data Records
}

Landsat Surface Reflectance Climate Data Records (CDRs) are high level Landsat data products that support land surface change studies. Climate Data Records, as defined by the National Research Council, are a time series of measurements with sufficient length, consistency, and continuity to identify climate variability and change. The U.S. Geological Survey (USGS) is using the valuable 40-year Landsat archive to create CDRs that can be used to document changes to Earth's terrestrial environment.

Landsat Surface Reflectance CDRs are generated using Landsat Ecosystem Disturbance Adaptive Processing System (LEDAPS) software, which applies Moderate Resolution Imaging Spectroradiometer (MODIS) atmospheric correction routines to Landsat Level-1 scenes.
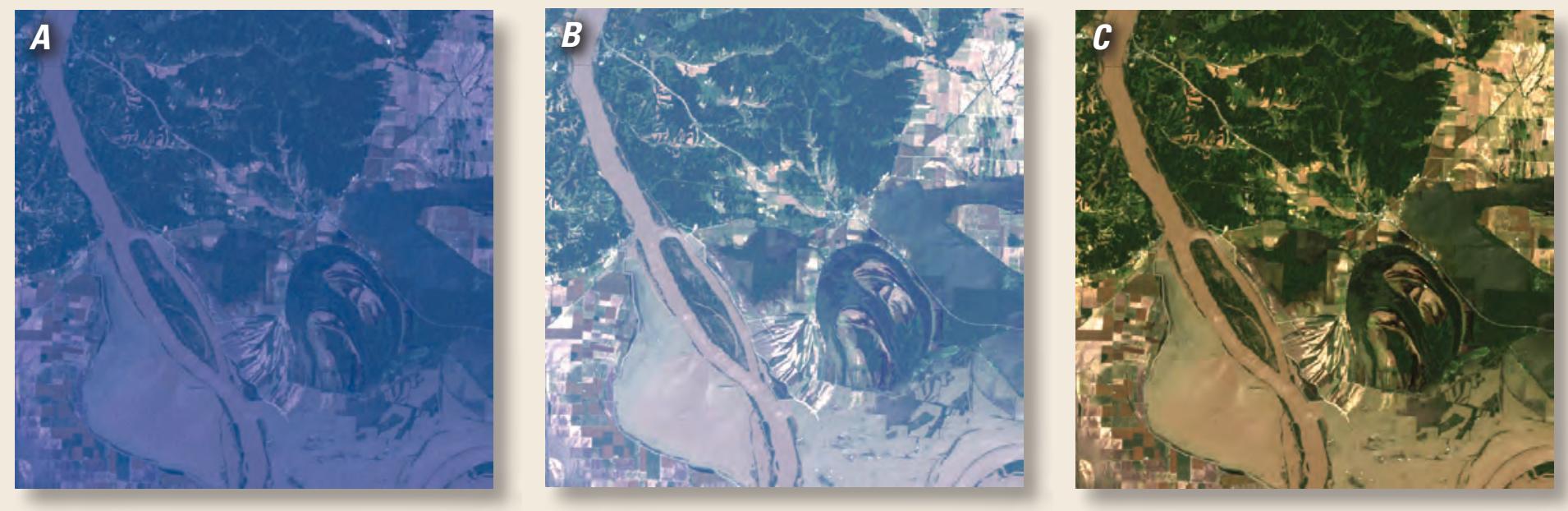

Subsets of a Landsat scene, displaying $A$, the natural color of a Level-1 product; $B$, after applying Top-of-Atmosphere corrections; and $C$, the result of Surface Reflectance processing. [Source: Landsat 5 Thematic Mapper (TM) Path 23 Row 34, acquired May 30, 1995]

All Level-1 scenes meeting the following criteria can be processed to Surface Reflectance:

Landsat 7 All scenes acquired from 1999 to within 1 week of present acquisitions.

Landsat 4 and Landsat 5 Most scenes acquired from August 1982 to May 2012; some scenes are excluded because of processing system limitations.

Landsat 8 Expected to become available in 2014.
The following products are available as options when requests for surface reflectance processing are made through the on-demand USGS Earth Resources Observation and Science (EROS) Center Science Processing Architecture (ESPA) system (https://espa.cr.usgs.gov/):

- Source Products (Landsat Level-1 Product or Metadata, or both)

- Top-of-Atmosphere Reflectance [Hierarchical Data Format for Earth Observing System (HDF-EOS) data format]

- Surface Reflectance (SR) (HDF-EOS data format)

- Band 6 Brightness Temperature (HDF-EOS data format)

Reprojection, user-defined image extents, and pixel resizing also are options for ESPA-submitted data products. Surface reflectance data processing requests for individual Landsat scenes can be placed by accessing EarthExplorer (http://earthexplorer.usgs.gov).

More information about Landsat Surface Reflectance CDRs can be accessed at http://landsat.usgs.gov/CDR_LSR.php.

Contact Landsat User Services (http://landsat.usgs.gov/contactus.php) with any questions about Landsat CDRs. 